\title{
Long-term observational study in Japanese hemodialysis patients who completed a 3-year clinical study of lanthanum carbonate
}

Takashi Shigematsu*, Shigeo Negi and Masaki Ohya

\begin{abstract}
Background: Lanthanum carbonate (LC), an effective phosphate (P) binder, is widely used to manage hyperphosphatemia in hemodialysis patients. However, the long-term safety of LC treatment in clinical practice has not been completely established.

Methods: In an observational multicenter study, we retrospectively investigated the long-term tolerability in Japanese hemodialysis patients who had completed a 3-year phase III extension study of LC. Among 39 patients who completed the phase III extension study, those who gave written informed consent to allow a retrospective examination of their medical records for up to 8 years were enrolled. During the period spanning 2009 to 2013, a tolerability assessment was performed by monitoring adverse events, laboratory parameters, and vital signs.

Results: Among the 34 enrolled patients, 30 were included for analysis. In this 5-year follow-up observational study, 18 of 30 patients (60.0\%) received LC with or without some other P binders (PBs), 10 patients (33.3\%) switched from LC to another PB, and 2 patients (6.7\%) did not use PB. During the phase III study, 16 patients (53.3\%) experienced a drug-related adverse event, with the most common being gastrointestinal disorder, already known to be a common adverse event of LC. No drug-related adverse events were reported during the follow-up observational study. Five of 18 patients (27.8 \%) who continued LC and 3 of 12 patients (25.0\%) who did not continue LC experienced serious adverse events during the follow-up observational study. However, none of these events except for constipation were drug-related. Mean serum P concentrations was kept within the guideline-recommended management target range during the study period. No clinically significant changes in laboratory parameters and vital signs were observed except for pronounced decreases in intact parathyrois hormone (PTH) and blood pressure during the follow-up observational study period.
\end{abstract}

Conclusions: In patients who completed a 3-year phase III extension study of LC, there was no evidence of delayed adverse events or any increase in the incidence of LC-related adverse events with increasing LC exposure for up to 8 years.

Trial registration: UMIN-CTR UMIN000015227

Keywords: Lanthanum carbonate, Phosphate binders, Hemodialysis, Hyperphosphatemia

\footnotetext{
* Correspondence: taki@wakayama-med.ac.jp

Department of Nephrology, Wakayama Medical University, 811-1 Kimiidera,

Wakayama city, Wakayama 641-8509, Japan
} 


\section{Background}

In chronic kidney disease (CKD) patients, urinary excretion of phosphate $(\mathrm{P})$ is compromised due to renal failure, and hyperphosphatemia is therefore likely to occur. When hyperphosphatemia persists for a prolonged period, the risk of cardiovascular disease due to vascular calcification increases, resulting in extremely poor patient prognosis [1-5]. Consequently, the longterm management of the serum $\mathrm{P}$ concentration in dialysis patients is considered to be an important risk management item for improving patient prognosis. The "Clinical Practice Guideline for the Management of Chronic Kidney Disease-Mineral and Bone Disorder" published by the Japanese Society for Dialysis Therapy (JSDT) recommends that serum $\mathrm{P}$ concentrations be managed within the range of 3.5 to $6.0 \mathrm{mg} / \mathrm{dL}$ [6].

Lanthanum carbonate (LC), an effective non-calcium (Ca) P binder (PB), is widely used to manage hyperphosphatemia in patients with CKD on dialysis. Studies evaluating the efficacy and safety of LC administration over 2, 3, and 6 years have consistently reported that LC is well tolerated with no evidence of safety-related issues [7-10]. Despite this evidence supporting its safety, concerns over the long-term safety of LC persist because some reports have suggested the potential risks of lanthanum (La) deposition and toxicity in the gastrointestinal tract, bone, liver, and central nervous system [11-15]. These safety concerns would appear to be at least partially based on the known toxicities of aluminium (Al)-containing $\mathrm{P}$ binders (PBs), which were commonly used between 1970 and 1990. Accumulation of $\mathrm{Al}$ due to long-term use of these binders in patients with CKD caused serious complications including encephalopathy, osteomalacia, proximal myopathy and microcytic anaemia [16]. Consequently, Al-containing PBs were contraindicated in 1992 for use in dialysis patients. A recently reported systematic review and metaanalysis of randomized controlled trials concluded that LC is well tolerated and more effective than placebo on a short-term basis in the treatment of hyperphosphatemia in dialysis patients, but its long-term tolerability and safety still needs further investigation [17].

Therefore, in this observational multicenter study, we retrospectively investigated long-term (for up to 8 years) tolerability in Japanese hemodialysis patients who had completed a 3-year clinical study of LC [10].

\section{Methods}

\section{Study design and patients}

This was a retrospective, observational multicenter study conducted at 10 Japanese dialysis facilities in patients with end stage renal disease (ESRD) undergoing hemodialysis and who had completed the 3-year phase III extension study of LC. The phase III study consisted of the original 1-year open-label study [18] and an additional 2-year open-label study [10]. One hundred and forty-five patients were enrolled in the phase III study, and after 1 year of treatment, 63 patients continued with further LC treatment for up to 3 years [10]. Among the 39 hemodialysis patients who completed the phase III study, patients who gave written informed consent to allow the retrospective examination of their medical records for up to 8 years (including the 3 -year period of the phase III study) were enrolled in this follow-up observational study. Five patients who were assigned to placebo during the 6-week double-blind phase were excluded from being potential study candidates. The original 1-year study was performed during 2005 and 2006, and an additional 2-year study was performed from 2006 to 2008. The study period of this follow-up observational study was from 2009 to 2013. The study was registered in UMIN-CTR: UMIN000015227.

\section{Assessments}

Using medical records, patient history including underlying diseases was examined at baseline of the phase III study. The primary endpoint was incidence of adverse events over a period of up to 8 years. Additionally, we investigated changes in the dosage of $\mathrm{LC}$ and $\mathrm{PB}$ other than LC and cinacalcet and the changes in biochemical and hematologic parameters and vital signs.

\section{Statistical analysis}

All variables were analysed by calculating descriptive statistics: frequency tables for categorical variables and the mean, standard deviation (SD) for continuous variables. The mean changes from baseline and their two-sided $95 \%$ confidence intervals were calculated for laboratory parameters and vital signs. Comparisons between continuous variables were performed using the Wilcoxon signed-rank test and paired $t$ test. In addition, we performed an ANOVA test. A value of $p<0.05$ was considered to be statistically significant.

\section{Ethics}

The study was conducted in accordance with principles that have their origin in the Declaration of Helsinki and the Ethical Guidelines for Clinical Studies published by Ministry of Health, Labour and Welfare. The central institutional review board at Wakayama Medical University approved the study protocol, and written informed consent was obtained from each patient before the enrollment. The investigators retrospectively examined the patients' medical records in a manner that fully protected the patients' privacy. 


\section{Results}

\section{Study patients}

Among the 34 patients who enrolled in this follow-up observational study, 30 patients were included for analysis, and 4 patients whose data were not available were excluded from analysis. The excluded patients consisted of 2 patients lost to follow-up, 1 patient who had a renal transplantation, and 1 patient who withdrew consent.

Table 1 shows the baseline demographic characteristics of the 30 study patients. The average age was 54.7 years, and the male/female ratio was $21 / 9$. The mean time on dialysis was 98.0 months, and the most common underlying disease was chronic glomerulonephritis, which was present in $50.0 \%$ of patients. A significant proportion of patients had complications commonly associated with dialysis such as renal anaemia, hypertension, and secondary hyperparathyroidism $(86.7,76.7$, and $70.0 \%$, respectively). The mean serum $\mathrm{P}$, corrected $\mathrm{Ca}$, and intact parathyrois hormone (PTH) concentrations were 7.8, 9.3, and $283.1 \mathrm{pg} / \mathrm{mL}$, respectively.

\section{Changes in the dosage of phosphate binders and cinacalcet}

Following manufacturing and marketing approval in October 2008, LC was launched onto the market in

Table 1 Baseline demographic characteristics of the study patients

\begin{tabular}{|c|c|}
\hline & Total $(n=30)$ \\
\hline Age (year) & $54.7 \pm 10.9$ \\
\hline \multicolumn{2}{|l|}{ Sex } \\
\hline Male (n) & $21(61.8 \%)$ \\
\hline Female $(n)$ & $9(26.5 \%)$ \\
\hline \multirow[t]{2}{*}{ Dry weight (kg) } & $62.4 \pm 7.4$ (Male) \\
\hline & $50.6 \pm 8.3$ (Female) \\
\hline Time on dialysis (months) & $98.0 \pm 82.3$ \\
\hline \multicolumn{2}{|l|}{ Underlying diseases causing renal failure } \\
\hline Chronic glomerulonephritis ( $n$ ) & $15(50.0 \%)$ \\
\hline Diabetic nephropathy $(n)$ & $8(26.7 \%)$ \\
\hline Chronic pyelonephritis ( $n$ ) & $2(6.7 \%)$ \\
\hline IgA nephropathy $(n)$ & $2(6.7 \%)$ \\
\hline Polycystic kidney (n) & $2(6.7 \%)$ \\
\hline Focal sclerosing glomerulonephritis ( $n$ ) & $1(3.3 \%)$ \\
\hline \multicolumn{2}{|l|}{ Complications } \\
\hline Renal anemia $(n)$ & $26(86.7 \%)$ \\
\hline Hypertension ( $n$ ) & $23(76.7 \%)$ \\
\hline Secondary hyperparathyroidism (n) & $21(70.0 \%)$ \\
\hline Serum P (mg/dL) & $7.8 \pm 1.6$ \\
\hline Serum corrected Ca (mg/dL) & $9.3 \pm 0.6$ \\
\hline Serum intact PTH $(\mathrm{pg} / \mathrm{mL})$ & $283.1 \pm 152.4$ \\
\hline
\end{tabular}

Data are given as mean \pm standard deviation or number $P$ phosphate, $C a$ calcium
March 2009. This meant that LC had not been released for general clinical use during the final stages of the phase III study. Thus, LC could not be used for a certain period until it was adopted by dialysis facilities following its release onto the market.

The mean dose of LC at the start of the phase III study was $1700.0 \pm 879.4 \mathrm{mg} /$ day. This dosage was generally maintained during the phase III study, but was reduced following the phase III study because 18 of 30 patients $(60.0 \%)$ received LC with or without some other PBs such as Ca carbonate or sevelamer hydrochloride. In 10 of 30 patients $(33.3 \%)$, the PB was switched from LC to another $\mathrm{PB}$, and in 2 of 30 patients (6.7\%) PB was no longer used. After cinacalcet was launched in January 2008 , there was a steady yearly increase in the number of patients receiving this drug during the follow-up observational study. The mean dose of cinacalcet at the start of the follow-up observational study was $40.0 \pm$ $12.9 \mathrm{mg} /$ day, and this dose was generally maintained for the duration of the study (Table 2).

\section{Incidence of adverse events}

Drug (LC)-related adverse events that occurred during the phase III study are listed in Table 3. Sixteen patients (53.3 \%) experienced a drug-related adverse event during the phase III study. None of the 30 patients experienced any drug-related (any PB including LC) adverse events during the 5-year follow-up observational study.

A total of 16 patients experienced 103 cases of drugrelated adverse events, but all of these events except for 1 event were not serious. The 1 serious adverse event was constipation reported as "worsening of constipation" by the investigator and which resolved without treatment. The most common drug-related adverse events were nausea and vomiting, which occurred in 12 patients (40.0\%).

Serious adverse events that occurred during the phase III study and 5-year follow-up observational study are listed in Table 4. None of these serious adverse events except 1 event (constipation mentioned above) were drug-related. There were 3 deaths. The causes of death were cardiac failure ( 2 cases) and 1 case of pneumonia. Two patients $(6.7 \%)$ experienced a serious adverse event during the phase III study. During the 5-year follow-up observational study, 5 of 18 patients $(27.8 \%)$ who continued LC use and 3 of 12 patients (25.0\%) who did not continue LC (10 patients switched to another $\mathrm{PB}$ and 2 patients did not use $\mathrm{PB}$ ) experienced serious adverse events.

\section{Mean serum $\mathrm{P}$ concentrations}

Figure 1 shows the changes from baseline (at the start of phase III study) in mean serum $\mathrm{P}$ concentrations during the 8-year study period. Mean serum $\mathrm{P}$ concentrations 
Table 2 Dosage changes in phosphate binders and cinacalcet

\begin{tabular}{|c|c|c|c|c|c|c|c|c|c|}
\hline \multirow[b]{2}{*}{ Dosage (mg/day) } & \multicolumn{4}{|c|}{ Phase III study (1-year study and additional 2-year study) } & \multicolumn{5}{|c|}{ 5-year follow-up observational study } \\
\hline & Start (2005) & 1 year after (2006) & $\begin{array}{l}2 \text { years after } \\
(2007)\end{array}$ & $\begin{array}{l}3 \text { years after } \\
\text { (2008) }\end{array}$ & $\begin{array}{l}4 \text { years after } \\
\text { (2009) }\end{array}$ & $\begin{array}{l}5 \text { years after } \\
(2010)\end{array}$ & $\begin{array}{l}6 \text { years after } \\
(2011)\end{array}$ & $\begin{array}{l}7 \text { years after } \\
(2012)\end{array}$ & $\begin{array}{l}8 \text { years after } \\
\text { (2013) }\end{array}$ \\
\hline Lanthanum carbonate & $\begin{array}{l}1700.0 \pm 879.4 \\
(750-3000) \\
(n=30)\end{array}$ & $\begin{array}{l}1625.0 \pm 966.6 \\
(750-3750) \\
(n=30)\end{array}$ & $\begin{array}{l}1525.0 \pm 775.0 \\
(750-3750) \\
(n=30)\end{array}$ & $\begin{array}{l}1550.0 \pm 834.1 \\
(750-3750) \\
(n=30)\end{array}$ & $\begin{array}{l}1500 \\
(n=1)\end{array}$ & $\begin{array}{l}863.6 \pm 452.3 \\
(250-1500) \\
(n=11)\end{array}$ & $\begin{array}{l}1113.6 \pm 563.1 \\
(500-2250) \\
(n=11)\end{array}$ & $\begin{array}{l}970.6 \pm 413.5 \\
(250-1500) \\
(n=17)\end{array}$ & $\begin{array}{l}1125.0 \pm 413.5 \\
(500-1500) \\
(n=18)\end{array}$ \\
\hline Calcium carbonate & - & - & - & - & $\begin{array}{l}2035.7 \pm 929.7 \\
(250-3000) \\
(n=21)\end{array}$ & $\begin{array}{l}2133.3 \pm 766.9 \\
(1000-3000) \\
(n=15)\end{array}$ & $\begin{array}{l}2125.0 \pm 974.7 \\
(1000-4500) \\
(n=16)\end{array}$ & $\begin{array}{l}2318.2 \pm 783.3 \\
(1500-3000) \\
(n=11)\end{array}$ & $\begin{array}{l}1792.3 \pm 950.0 \\
(300-3000) \\
(n=13)\end{array}$ \\
\hline Sevelamer hydrochloride & - & - & - & - & $\begin{array}{l}1968.8 \pm 1263.8 \\
(750-4500) \\
(n=8)\end{array}$ & $\begin{array}{l}2035.7 \pm 940.2 \\
(750-3750) \\
(n=7)\end{array}$ & $\begin{array}{l}1875.0 \pm 1131.9 \\
(750-3750) \\
(n=10)\end{array}$ & $\begin{array}{l}1607.1 \pm 1097.9 \\
(750-3750) \\
(n=7)\end{array}$ & $\begin{array}{l}1821.4 \pm 954.3 \\
(750-3750) \\
(n=7)\end{array}$ \\
\hline Cinacalcet hydrochloride & - & - & - & - & $\begin{array}{l}40.0 \pm 12.9 \\
(25-50) \\
(n=10)\end{array}$ & $\begin{array}{l}44.2 \pm 18.1 \\
(25-75) \\
(n=13)\end{array}$ & $\begin{array}{l}41.4 \pm 21.8 \\
(25-100) \\
(n=16)\end{array}$ & $\begin{array}{l}42.5 \pm 19.9 \\
(25-75) \\
(n=15)\end{array}$ & $\begin{array}{l}39.8 \pm 17.8 \\
(25-75) \\
(n=16)\end{array}$ \\
\hline
\end{tabular}


Table 3 Drug-related adverse events during the phase III study

\begin{tabular}{lll}
\hline $\begin{array}{l}\text { Drug-related adverse events } \\
\text { (SOC/PT) }\end{array}$ & Patients with events, $16 / 30$ (53.3 \%) \\
\cline { 2 - 3 } & Number of patients & Number of events \\
\hline Endocrine disorders & 5 \\
Hyperparathyroidism & 5 \\
Gastrointestinal disorders & 12 & 41 \\
Vomiting & 12 & 26 \\
Nausea & 4 & 4 \\
Abdominal discomfort & 3 & 5 \\
Abdominal pain, upper & 2 & 7 \\
Diarrhoea & 2 & 2 \\
Constipation & 1 & 1 \\
Abdominal pain, lower & 1 & 1 \\
Faeces, soft & 1 & 9 \\
General disorders and administration site conditions & \\
Flank pain & 1 & 1 \\
Chest discomfort & & 1 \\
Investigations & 1 & \\
C-reactive protein increased & & \\
\hline
\end{tabular}

SOC System Organ Class, PT Preferred Term (MedDRA ver. 18.0)

decreased from $7.8 \mathrm{mg} / \mathrm{dL}$ at baseline to $5.2 \mathrm{mg} / \mathrm{dL}$ after 3 years and $5.3 \mathrm{mg} / \mathrm{dL}$ after 8 years, thus remaining within the management target range $(3.5-6.0 \mathrm{mg} / \mathrm{dL}$ ) recommended in the JSDT guidelines [6] during the entire study period (Fig. 1a). The mean serum P concentration in patients who continued LC use did not differ significantly from that observed in the patients who did not continue LC (Fig. 1b).

\section{Laboratory parameters and vital signs}

Laboratory parameters and vital signs of all patients are shown in Table 5. Several parameters and vital signs showed statistically significant changes after 4 or 8 years. Of those parameters, the decrease in intact PTH and blood pressure would appear to be clinically significant. The mean changes from baseline after 8 years were $-103.45 \mathrm{pg} / \mathrm{mL},-18.83 \mathrm{mmHg}$ (systolic blood pressure (SBP)), and $-13.39 \mathrm{mmHg}$ (diastolic blood pressure (DBP)), respectively. Table 6 shows the laboratory parameters and vital signs of patients who continued to receive LC. In those patients, the summary statistics did not differ from those observed in all patients.

\section{Discussion}

LC is widely used to manage hyperphosphatemia in patients with CKD on dialysis and has contributed to improved clinical outcomes in these patients. The short-term safety profile of LC has been reported [19]; the most common adverse events of $\mathrm{LC}$ - and $\mathrm{Ca}$ - containing $\mathrm{PB}$ were gastrointestinal reactions. No significant difference was found in nausea (RR 1.72, $95 \%$ CI 1.00-2.98, $p=0.05$ ), vomiting (RR 2.17, $95 \% \mathrm{CI}$ $0.87-5.41, p=0.10$ ), diarrhoea (RR 1.26, $95 \%$ CI $0.84-$ $1.89, p=0.27$ ), or constipation (RR 0.78, $95 \%$ CI 0.50 $1.21, p=0.27$ ) between the two treatments.

Some studies were evaluated the efficacy, tolerability, and safety of LC monotherapy over 2 years [7], 3 years [8], and 6 years [9] have consistently reported that LC is well tolerated, with no evidence of safety concerns. The majority of LC adverse drug reactions were related to the gastro-intestinal tract (mainly nausea, diarrhoea, and flatulence) [9] and are primarily mild/moderate in severity, consistent with those observed with other phosphate binders. However, there is no insufficient safety data for a prolonged period or for Japanese.

Accordingly, the authors think that it is important to accumulate more evidence of the long-term effects of LC treatment in the clinical practice and explore how LC can be used for a prolonged period in a safe and appropriate manner.

Therefore, we retrospectively investigated the longterm tolerability of LC among Japanese hemodialysis patients who completed the phase III study study of LC treatment, in an observational multicenter study in order to follow safety outcomes for further 5 years regardless of these patients' LC administration. In this follow-up observational study, 18 of 30 patients $(60.0 \%)$ received LC with or without some other PBs, and in 10 of $30 \mathrm{pa}-$ tients (33.3\%), the PB was switched from LC to another $\mathrm{PB}$ and in 2 of 30 patients (6.7 \%) PB was no longer used.

During the phase III study, LC-related adverse events occurred in 16 patients (53.3\%); however, no adverse events that were considered by the investigators to be related to any $\mathrm{PB}$, including $\mathrm{LC}$, were reported during the 5-year follow-up observational study. Although the dosage of LC was reduced in some patients and other patients switched to another PB from LC after the phase III study, these results strongly suggest that no evidence exists of delayed adverse events after 3 years of LC exposure or any increase in the incidence of LC-related adverse events with increasing $\mathrm{LC}$ exposure.

The most common drug-related adverse events that occurred during the phase III study were vomiting and nausea, which are already known to be common adverse events associated with LC [20]; however, there were no treatment discontinuations due to gastrointestinal adverse events. Hutchison et al. reported that no gastrointestinal events occurred in US patients after 3 years of LC exposure or in European patients after 4 years of exposure [9]. These results indicate that long-term LC treatment is possible provided gastrointestinal events that tend to occur more frequently in the early phase of treatment can be controlled. 
Table 4 Serious adverse events during the phase III study and 5-year follow-up observational study

\begin{tabular}{|c|c|c|c|c|c|c|}
\hline & \multicolumn{2}{|c|}{ Patients with events 2/30 (6.7 \%) } & \multicolumn{2}{|c|}{$\begin{array}{l}\text { Patients who continue LC } \\
\text { Patients with events 5/18 (27.8\%) }\end{array}$} & \multicolumn{2}{|c|}{$\begin{array}{l}\text { Patients who did not continue LC } \\
\text { Patients with events } 3 / 12(25.0 \%)\end{array}$} \\
\hline & $\begin{array}{l}\text { Number } \\
\text { of patients }\end{array}$ & $\begin{array}{l}\text { Number } \\
\text { of events }\end{array}$ & $\begin{array}{l}\text { Number } \\
\text { of patients }\end{array}$ & $\begin{array}{l}\text { Number } \\
\text { of events }\end{array}$ & $\begin{array}{l}\text { Number } \\
\text { of patients }\end{array}$ & $\begin{array}{l}\text { Number } \\
\text { of events }\end{array}$ \\
\hline \multicolumn{7}{|l|}{ Infections and infestations } \\
\hline Gangrene & & & 1 & 1 & & \\
\hline Pneumonia & & & & & $1^{a}$ & 1 \\
\hline Pyelonephritis acute & 1 & 1 & & & & \\
\hline \multicolumn{7}{|c|}{ Neoplasms benign, malignant, and unspecified (including cysts and polyps) } \\
\hline Colon cancer & & & & & 1 & 1 \\
\hline \multicolumn{7}{|l|}{ Nervous system disorder } \\
\hline Cerebral haemorrhage & & & & & 1 & 1 \\
\hline \multicolumn{7}{|l|}{ Cardiac disorders } \\
\hline Myocardial ischaemia & & & 1 & 1 & & \\
\hline Tachycardia & & & 1 & 1 & & \\
\hline Cardiac valve disease & & & 1 & 1 & & \\
\hline Cardiac failure & & & 1 & 1 & & \\
\hline Cardiac failure acute & & & & & $1^{a}$ & 1 \\
\hline \multicolumn{7}{|l|}{ Vascular disorders } \\
\hline Peripheral arterial occlusive disease & & & 2 & 2 & 1 & 1 \\
\hline \multicolumn{7}{|l|}{ Gastrointestinal disorders } \\
\hline Constipation & 1 & 1 & & & & \\
\hline Upper gastrointestinal haemorrhage & & & 1 & 1 & & \\
\hline \multicolumn{7}{|l|}{ Surgical and medical procedures } \\
\hline Foot amputation & & & 1 & 1 & & \\
\hline \multicolumn{7}{|c|}{ General disorders and administration site conditions } \\
\hline Death & & & $1^{a}$ & 1 & & \\
\hline
\end{tabular}

${ }^{a}$ Outcome was death
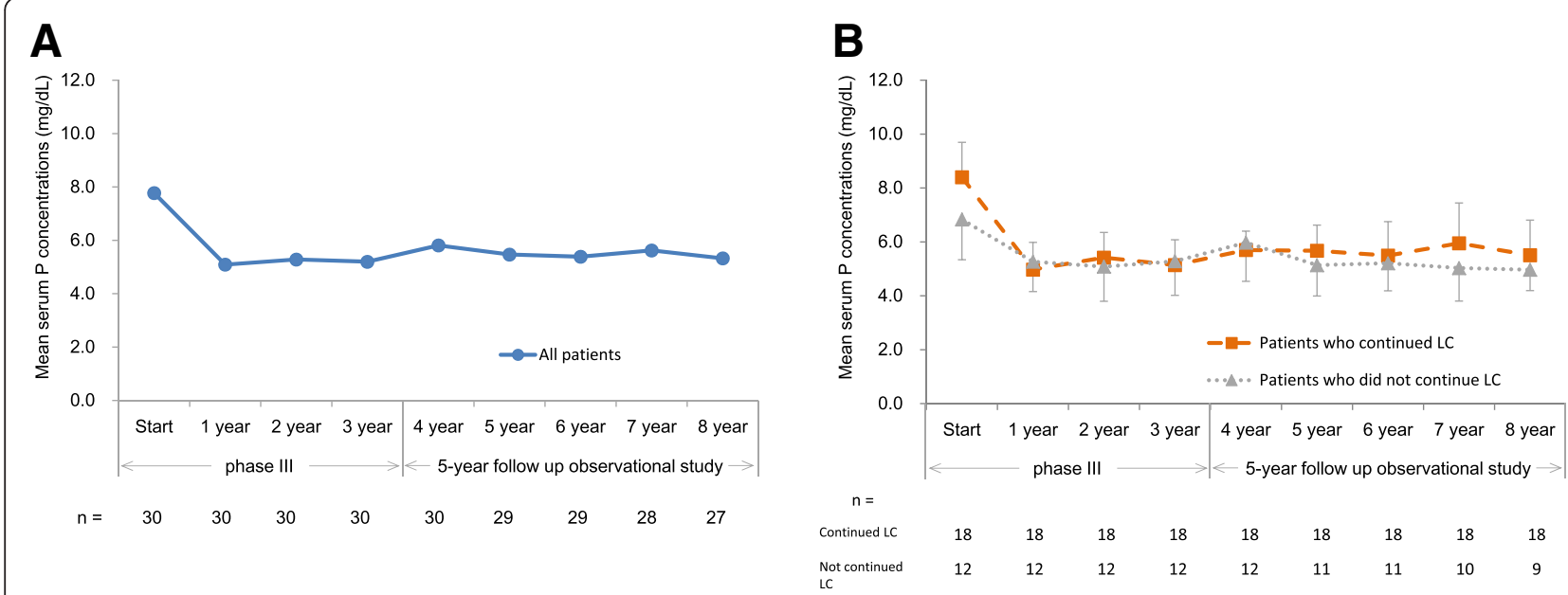

Fig. 1 Mean serum P concentrations at the start of phase III study and at various time points over the 8-year period covered by the study. a All patients, $\mathbf{b}$ Patients who continued LC or did not continue LC. Data are given as mean \pm standard deviation ( $\mathrm{n}=$ number of patients in a specific year) 
Table $\mathbf{5}$ Laboratory parameters and vital signs of all patients

\begin{tabular}{|c|c|c|c|c|c|}
\hline Parameters & Start & 4 years after & 8 years after & $\begin{array}{l}4 \text { years mean change } \pm \text { SEM } \\
(95 \% \mathrm{Cl})\end{array}$ & $\begin{array}{l}8 \text { years mean change } \pm \text { SEM } \\
(95 \% \mathrm{Cl})\end{array}$ \\
\hline $\mathrm{P}(\mathrm{mg} / \mathrm{dL})$ & $7.8 \pm 1.6$ & $5.8 \pm 1.0^{* * *}$ & $5.3 \pm 1.2^{* * *}$ & $-2.19 \pm 0.29(-2.80,-1.59)^{* * *}$ & $-.51 \pm 0.35(-3.24,-1.79)^{* * *}$ \\
\hline Corrected Ca (mg/dL) & $9.3 \pm 0.6$ & $9.2 \pm 0.5$ & $9.4 \pm 0.6$ & $-0.11 \pm 0.13(-0.38,0.16)$ & $0.11 \pm 0.11(-0.12,0.34)$ \\
\hline Intact PTH (pg/mL) & $283.1 \pm 152.4$ & $180.7 \pm 126.6^{* * *}$ & $179.1 \pm 131.7^{*}$ & $-103.95 \pm 27.20(-160.55,-47.35)^{* * *}$ & $-103.45 \pm 43.91(-194.76,-12.14)^{*}$ \\
\hline $\mathrm{Na}(\mathrm{mEq} / \mathrm{L})$ & $139.2 \pm 3.0$ & $138.5 \pm 2.4$ & $138.3 \pm 3.3^{*}$ & $-0.89 \pm 0.62(-2.17,0.38)$ & $-1.20 \pm 0.66(-2.56,0.16)^{*}$ \\
\hline $\mathrm{K}(\mathrm{mEq} / \mathrm{L})$ & $5.0 \pm 0.7$ & $5.4 \pm 0.7$ & $5.0 \pm 0.8$ & $0.39 \pm 0.10(0.19,0.60)$ & $-0.05 \pm 0.13(-0.33,0.22)$ \\
\hline $\mathrm{Cl}(\mathrm{mEq} / \mathrm{L})$ & $100.8 \pm 3.4$ & $102.9 \pm 3.6$ & $102.0 \pm 3.4$ & $1.85 \pm 0.79(0.23,3.47)$ & $1.07 \pm 0.83(-0.63,2.78)$ \\
\hline Glucose (mg/dL) & $128.6 \pm 51.9$ & $123.9 \pm 53.3$ & $113.9 \pm 37.2$ & $17.00 \pm 23.91(-37.08,71.08)$ & $2.90 \pm 8.10(-15.43,21.23)$ \\
\hline $\mathrm{CRP}(\mathrm{mg} / \mathrm{dL})$ & $0.2 \pm 0.2$ & $0.6 \pm 1.3$ & $0.6 \pm 1.0$ & $0.29 \pm 0.19(-0.11,0.70)$ & $0.37 \pm 0.22(-0.09,0.83)$ \\
\hline $\mathrm{RBC}(\times 104 / \mu \mathrm{L})$ & $327 \pm 39$ & $356 \pm 32$ & $361 \pm 36$ & $0.31 \pm 0.08(0.15,0.47)$ & $0.34 \pm 0.08(0.18,0.50)$ \\
\hline WBC $(/ \mu \mathrm{L})$ & $5803 \pm 1474$ & $6190 \pm 2028$ & $5891 \pm 1977$ & $0.44 \pm 0.28(-0.13,1.01)$ & $0.16 \pm 0.27(-0.40,0.71)$ \\
\hline $\mathrm{Hb}(\mathrm{g} / \mathrm{dL})$ & $10.5 \pm 1.1$ & $11.2 \pm 1.3$ & $10.8 \pm 1.1$ & $0.48 \pm 0.26(-0.04,1.01)$ & $0.26 \pm 0.26(-0.28,0.79)$ \\
\hline $\mathrm{Ht}(\%)$ & $31.8 \pm 3.6$ & $34.7 \pm 2.6$ & $33.9 \pm 2.6$ & $3.00 \pm 0.73(1.51,4.51)$ & $2.06 \pm 0.70(0.62,3.49)$ \\
\hline Plt $(\times 104 / \mu \mathrm{L})$ & $19.8 \pm 4.4$ & $19.7 \pm 6.6$ & $20.2 \pm 6.7$ & $0.03 \pm 1.04(-2.21,2.18)$ & $2.06 \pm 0.70(0.62,3.49)$ \\
\hline Serum Alb (g/dL) & $4.0 \pm 0.3$ & $3.9 \pm 0.3^{*}$ & $3.6 \pm 0.3^{* * *}$ & $-0.13 \pm 0.05(-0.23,-0.02)^{*}$ & $-0.43 \pm 0.06(-0.56,-0.31)^{* * *}$ \\
\hline $\operatorname{ALP}(U / L)$ & $237.3 \pm 110.1$ & $242.6 \pm 85.0$ & $262.9 \pm 95.1$ & $2.19 \pm 18.32(-35.54,39.92)$ & $10.88 \pm 17.59(-25.34,47.12)$ \\
\hline $\mathrm{LDH}(\mathrm{IU} / \mathrm{L})$ & $168.0 \pm 30.5$ & $173.9 \pm 33.5$ & $195.5 \pm 47.4$ & $5.65 \pm 6.52(-7.86,19.16)$ & $23.91 \pm 7.45(8.46,39.37)$ \\
\hline AST (U/L) & $11.7 \pm 6.4$ & $10.9 \pm 4.2$ & $17.8 \pm 16.5$ & $-0.85 \pm 1.27(-3.47,1.76)$ & $5.85 \pm 3.31(-0.95,12.65)$ \\
\hline $\operatorname{ALT}(U / L)$ & $10.7 \pm 5.5$ & $10.3 \pm 7.2$ & $13.7 \pm 8.5$ & $-0.37 \pm 1.76(-3.99,3.25)$ & $2.85 \pm 1.80(-0.84,6.55)$ \\
\hline y GTP (U/L) & $20.5 \pm 12.6$ & $26.1 \pm 31.5$ & $28.2 \pm 19.1$ & $8.46 \pm 6.75(-5.51,22.43)$ & $9.38 \pm 3.66(1.81,16.94)$ \\
\hline Total bilirubin (mg/dL) & $0.2 \pm 0.1$ & $0.3 \pm 0.1$ & $0.3 \pm 0.1$ & $0.04 \pm 0.02(-0.01,0.09)$ & $0.05 \pm 0.03(-0.01,0.12)$ \\
\hline Creatinine (mg/dL) & $12.7 \pm 2.0$ & $12.3 \pm 1.8$ & $11.2 \pm 2.0^{* * *}$ & $-0.30 \pm 0.33(-0.98,0.37)$ & $-1.40 \pm 0.32(-2.07,-0.74)^{* * *}$ \\
\hline Uric acid (mg/dL) & $8.5 \pm 1.2$ & $8.0 \pm 1.5$ & $7.7 \pm 1.4^{* *}$ & $-0.44 \pm 0.31(-1.09,0.21)$ & $-0.84 \pm 0.32(-1.50,-0.17)^{* *}$ \\
\hline $\mathrm{BUN}(\mathrm{mg} / \mathrm{dL})$ & $72.1 \pm 12.0$ & $69.6 \pm 12.5$ & $62.6 \pm 16.6^{* *}$ & $-0.99 \pm 3.02(-7.21,5.22)$ & $-9.81 \pm 2.90(-15.78,-3.84)^{* *}$ \\
\hline BUN after dialysis (mg/dL) & $23.6 \pm 7.0$ & $20.0 \pm 5.7^{* *}$ & $16.8 \pm 6.0^{* * *}$ & $-3.85 \pm 1.37(-6.68,-1.02)^{* *}$ & $-7.39 \pm 1.32(-10.1,-4.66)^{* * *}$ \\
\hline $\mathrm{TG}(\mathrm{mg} / \mathrm{dL})$ & $132.0 \pm 66.0$ & $121.8 \pm 76.7$ & $110.2 \pm 46.3$ & $10.53 \pm 18.02(-27.33,48.38)$ & $-5.11 \pm 10.69(-27.57,17.36)$ \\
\hline Total cholesterol (mg/dL) & $178.0 \pm 33.4$ & $161.8 \pm 37.9$ & $171.0 \pm 39.2$ & $-7.56 \pm 5.43(-19.13,4.00)$ & $-2.00 \pm 8.45(-20.01,16.01)$ \\
\hline $\mathrm{HDL}-\mathrm{C}(\mathrm{mg} / \mathrm{dL})$ & $45.5 \pm 14.4$ & $51.0 \pm 14.2$ & $53.6 \pm 16.9$ & $5.16 \pm 2.27(0.40,9.92)$ & $6.42 \pm 2.29(1.62,11.2)$ \\
\hline $\mathrm{SBP}(\mathrm{mmHg})$ & $160.2 \pm 24.4$ & $144.2 \pm 21.4^{* * *}$ & $146.2 \pm 18.5^{* * *}$ & $-19.13 \pm 5.19(-29.89,-8.37)^{* * *}$ & $-18.83 \pm 4.81(-28.80,-8.86)^{* * *}$ \\
\hline $\mathrm{DBP}(\mathrm{mmHg})$ & $88.7 \pm 16.5$ & $79.6 \pm 12.6^{* *}$ & $77.4 \pm 13.2^{* * *}$ & $-10.26 \pm 3.69(-17.92,-2.6)^{* *}$ & $-13.39 \pm 2.25(-18.06,-8.73)^{* * *}$ \\
\hline HR (beats/min) & $77.1 \pm 12.0$ & $74.8 \pm 16.9$ & $75.0 \pm 13.3$ & $-2.26 \pm 2.79(-8.13,3.61)$ & $-2.74 \pm 3.00(-9.04,3.57)$ \\
\hline
\end{tabular}

Data are given as mean \pm standard deviation $(\mathrm{n})$

$\mathrm{Cl}$ confidence interval

V.S. At the start, ${ }^{* * *} P<0.001,{ }^{* *} P<0.01,{ }^{*} P<0.05$

Another potential safety concern of LC treatment is toxicity in bone, liver, and the central nervous system [11-15]. The long-term safety profile of LC in hemodialysis patients receiving treatment for up to 6 years have been reported and appear to show no evidence of adverse effects on the liver, bone, or the central nervous system [9].

Two patients $(6.7 \%)$ during the phase III study, 5 of 18 patients $(27.8 \%)$ who continued LC use and 3 of 12 patients $(25.0 \%)$ who did not continue LC experienced a serious adverse event during the 5 year follow-up observational study; however, all of these events except for 1 were not drug-related. The types of serious adverse events are those peculiar to dialysis patients with multiple complications. There was no difference in frequency of serious adverse events between patients who continued LC and patients who did not continue LC.

La deposition in a mesenteric lymph node found at autopsy of an ESRD patient 3 years after LC administration was reported [21]. Although the clinical significance of this deposition of $\mathrm{La}$ is not clear, further investigation of its potential long-term toxic effects is needed. Thus, the long-term safety of LC treatment, especially in clinical practice, has not been completely established. In recent years, several case reports about La deposition in gastric mucosa have been published [22-25]. Although 
Table 6 Laboratory parameters and vital signs of patients who continued LC use

\begin{tabular}{|c|c|c|c|c|c|c|c|c|c|}
\hline Parameters & Start & 1 year after & 2 years after & 3 years after & 4 years after & 5 years after & 6 years after & 7 years after & 8 years after \\
\hline $\mathrm{P}(\mathrm{mg} / \mathrm{dL})$ & $8.4 \pm 1.3$ & $5.0 \pm 1.0^{* * *}$ & $5.4 \pm 0.9^{* * *}$ & $5.1 \pm 0.9^{* * *}$ & $5.7 \pm 0.7^{* * *}$ & $5.7 \pm 0.9^{* * *}$ & $5.5 \pm 1.3^{* * *}$ & $6.0 \pm 1.5^{* * *}$ & $5.5 \pm 1.3^{* * *}$ \\
\hline Corrected Ca (mg/dL) & $9.2 \pm 0.6$ & $9.6 \pm 0.6$ & $9.6 \pm 0.6$ & $9.9 \pm 0.8$ & $9.2 \pm 0.5$ & $9.1 \pm 0.6$ & $9.2 \pm 0.5$ & $9.3 \pm 0.5$ & $9.3 \pm 0.7$ \\
\hline Intact PTH (pg/mL) & $334.6 \pm 164.4$ & $319.0 \pm 185.3$ & $353.4 \pm 186.2$ & $372.2 \pm 228.2$ & $218.9 \pm 141.2^{* *}$ & $204.3 \pm 136.4^{*}$ & $225.2 \pm 126.5^{*}$ & $185.7 \pm 111.6^{*}$ & $200.9 \pm 133.1^{*}$ \\
\hline $\mathrm{Na}(\mathrm{mEq} / \mathrm{L})$ & $138.9 \pm 3.4$ & $138.9 \pm 2.3$ & $139.1 \pm 3.3$ & $139.4 \pm 2.3$ & $138.3 \pm 2.3$ & $137.7 \pm 2.5$ & $138.4 \pm 3.0$ & $137.3 \pm 3.0^{*}$ & $138.8 \pm 2.7$ \\
\hline $\mathrm{K}(\mathrm{mEq} / \mathrm{L})$ & $5.1 \pm 0.8$ & $5.1 \pm 0.7$ & $5.3 \pm 0.6$ & $5.2 \pm 0.7$ & $5.4 \pm 0.6$ & $5.1 \pm 0.7$ & $5.4 \pm 0.7$ & $5.3 \pm 0.4$ & $5.1 \pm 0.7$ \\
\hline $\mathrm{Cl}(\mathrm{mEq} / \mathrm{L})$ & $100.4 \pm 3.8$ & $100.4 \pm 3.0$ & $100.8 \pm 3.8$ & $100.9 \pm 3.4$ & $101.9 \pm 3.6$ & $100.6 \pm 3.5$ & $101.1 \pm 4.1$ & $99.3 \pm 2.9$ & $101.2 \pm 3.4$ \\
\hline Glucose (mg/dL) & $129.0 \pm 62.1$ & $121.6 \pm 47.7$ & $121.4 \pm 40.9$ & $132.6 \pm 73.1$ & $139.3 \pm 63.9$ & $125.4 \pm 38.2$ & $132.2 \pm 54.8$ & $143.4 \pm 103.2$ & $108.1 \pm 34.2$ \\
\hline $\mathrm{CRP}(\mathrm{mg} / \mathrm{dL})$ & $0.2 \pm 0.2$ & $0.2 \pm 0.2$ & $0.1 \pm 0.1$ & $0.2 \pm 0.2$ & $1.0 \pm 1.7$ & $0.8 \pm 1.2$ & $0.5 \pm 0.9$ & $0.7 \pm 1.2$ & $0.8 \pm 1.2$ \\
\hline $\mathrm{RBC}(\times 104 / \mu \mathrm{L})$ & $331 \pm 39$ & $348 \pm 35$ & $344 \pm 28$ & $340 \pm 35$ & $356 \pm 36$ & $380 \pm 82$ & $360 \pm 30$ & $358 \pm 41$ & $362 \pm 40$ \\
\hline WBC $(/ \mu \mathrm{L})$ & $5800 \pm 1229$ & $6067 \pm 1435$ & $5856 \pm 1574$ & $6089 \pm 1386$ & $6533 \pm 2061$ & $6782 \pm 2136$ & $5911 \pm 1945$ & $6349 \pm 2030$ & $6126 \pm 1841$ \\
\hline $\mathrm{Hb}(\mathrm{g} / \mathrm{dL})$ & $10.6 \pm 1.0$ & $10.9 \pm 1.0$ & $10.6 \pm 0.9$ & $10.6 \pm 1.0$ & $11.1 \pm 0.8$ & $11.1 \pm 1.0$ & $11.0 \pm 0.8$ & $10.4 \pm 1.1$ & $11.0 \pm 1.0$ \\
\hline $\mathrm{Ht}(\%)$ & $32.0 \pm 3.9$ & $33.0 \pm 2.7$ & $32.4 \pm 2.3$ & $32.4 \pm 3.2$ & $34.3 \pm 3.1$ & $34.7 \pm 3.1$ & $34.2 \pm 2.4$ & $32.5 \pm 3.1$ & $33.8 \pm 2.8$ \\
\hline Plt $(\times 104 / \mu \mathrm{L})$ & $21.3 \pm 4.3$ & $21.5 \pm 3.2$ & $21.0 \pm 4.2$ & $21.4 \pm 4.6$ & $22.0 \pm 6.2$ & $22.3 \pm 6.1$ & $21.3 \pm 5.8$ & $23.1 \pm 5.9$ & $21.6 \pm 6.9$ \\
\hline Serum Alb (g/dL) & $4.1 \pm 0.2$ & $4.0 \pm 0.2$ & $4.1 \pm 0.2$ & $3.9 \pm 0.3$ & $3.9 \pm 0.3$ & $3.8 \pm 0.2$ & $3.9 \pm 0.3$ & $3.8 \pm 0.2$ & $3.6 \pm 0.3$ \\
\hline ALP $(U / L)$ & $238.8 \pm 129.5$ & $290.1 \pm 145.1$ & $307.2 \pm 166.1$ & $333.9 \pm 216.4$ & $228.8 \pm 83.4$ & $244.6 \pm 80.7$ & $258.1 \pm 102.5$ & $254.9 \pm 99.5$ & $270.7 \pm 107.9$ \\
\hline LDH (IU/L) & $172.2 \pm 33.4$ & $165.4 \pm 25.9^{*}$ & $170.1 \pm 26.8$ & $172.2 \pm 30.3$ & $175.4 \pm 36.7$ & $176.2 \pm 35.4$ & $189.8 \pm 48.8$ & $192.3 \pm 43.0$ & $199.1 \pm 56.9$ \\
\hline AST (U/L) & $11.3 \pm 6.8$ & $10.7 \pm 4.3$ & $11.9 \pm 3.4$ & $15.2 \pm 10.9$ & $11.1 \pm 3.8$ & $13.1 \pm 4.0$ & $14.3 \pm 4.5$ & $15.6 \pm 6.1$ & $19.9 \pm 19.8$ \\
\hline ALT $(U / L)$ & $10.3 \pm 5.9$ & $9.8 \pm 4.3$ & $11.2 \pm 7.2$ & $12.5 \pm 10.7$ & $11.1 \pm 9.0$ & $12.4 \pm 5.2$ & $14.6 \pm 7.4$ & $16.1 \pm 11.0$ & $15.7 \pm 9.7$ \\
\hline y GTP $(\mathrm{U} / \mathrm{L})$ & $18.7 \pm 9.7$ & $18.5 \pm 8.6$ & $34.2 \pm 63.4$ & $29.1 \pm 34.5$ & $28.9 \pm 38.8$ & $29.4 \pm 27.4$ & $26.8 \pm 19.2$ & $27.6 \pm 21.7$ & $29.7 \pm 20.8$ \\
\hline Total bilirubin (mg/dL) & $0.2 \pm 0.1$ & $0.2 \pm 0.1$ & $0.3 \pm 0.1$ & $0.2 \pm 0.1$ & $0.3 \pm 0.1$ & $0.3 \pm 0.1$ & $0.3 \pm 0.1$ & $0.2 \pm 0.0$ & $0.3 \pm 0.1$ \\
\hline Creatinine $(\mathrm{mg} / \mathrm{dL})$ & $13.1 \pm 1.9$ & $13.2 \pm 1.9$ & $12.7 \pm 1.9$ & $12.3 \pm 2.0$ & $12.4 \pm 1.9$ & $12.3 \pm 1.6^{*}$ & $11.8 \pm 1.7^{* *}$ & $11.7 \pm 2.1^{* *}$ & $11.5 \pm 2.2^{* * *}$ \\
\hline Uric acid (mg/dL) & $8.5 \pm 1.3$ & $8.3 \pm 1.0$ & $8.4 \pm 1.0$ & $8.1 \pm 1.1$ & $8.1 \pm 1.8$ & $8.3 \pm 1.1$ & $8.2 \pm 1.4$ & $8.2 \pm 1.6$ & $8.0 \pm 1.5$ \\
\hline BUN (mg/dL) & $76.1 \pm 10.5$ & $74.6 \pm 12.2$ & $72.2 \pm 13.8$ & $66.5 \pm 12.3^{* *}$ & $69.4 \pm 12.1^{*}$ & $72.2 \pm 14.5$ & $71.8 \pm 13.2$ & $67.2 \pm 9.7^{* *}$ & $66.7 \pm 14.9^{*}$ \\
\hline BUN after dialysis (mg/dL) & $25.8 \pm 6.4$ & $24.6 \pm 5.5$ & $22.8 \pm 5.5$ & $20.8 \pm 5.4^{* *}$ & $20.7 \pm 5.8^{* *}$ & $20.5 \pm 6.8^{* *}$ & $20.6 \pm 5.8^{* *}$ & $18.8 \pm 4.7^{* * *}$ & $18.5 \pm 5.2^{* * *}$ \\
\hline $\mathrm{TG}(\mathrm{mg} / \mathrm{dL})$ & $131.6 \pm 70.3$ & $145.4 \pm 86.4$ & $156.4 \pm 83.9$ & $125.3 \pm 72.5$ & $134.5 \pm 95.6$ & $130.6 \pm 69.3$ & $114.5 \pm 49.9$ & $128.1 \pm 74.7$ & $114.3 \pm 48.5$ \\
\hline Total cholesterol (mg/dL) & $175.4 \pm 33.6$ & $166.4 \pm 30.9$ & $181.1 \pm 39.8$ & $170.2 \pm 31.8$ & $157.5 \pm 27.6$ & $159.3 \pm 46.5$ & $182.4 \pm 38.1$ & $185.3 \pm 40.1$ & $176.7 \pm 38.0$ \\
\hline $\mathrm{HDL}-\mathrm{C}(\mathrm{mg} / \mathrm{dL})$ & $44.5 \pm 15.3$ & $43.4 \pm 12.6$ & $44.3 \pm 11.8$ & $46.1 \pm 13.8$ & $52.7 \pm 15.3$ & $49.3 \pm 13.1$ & $54.5 \pm 11.9$ & $49.6 \pm 12.4$ & $50.0 \pm 13.7$ \\
\hline $\mathrm{SBP}(\mathrm{mmHg})$ & $162.4 \pm 23.2$ & $160.1 \pm 21.9$ & $157.2 \pm 22.8$ & $153.3 \pm 17.4^{* *}$ & $149.8 \pm 16.6^{*}$ & $149.5 \pm 23.6^{* *}$ & $150.9 \pm 17.9^{*}$ & $141.3 \pm 22.5^{* *}$ & $144.2 \pm 17.6^{* *}$ \\
\hline $\mathrm{DBP}(\mathrm{mmHg})$ & $92.9 \pm 17.4$ & $89.1 \pm 17.5$ & $86.4 \pm 17.2^{* *}$ & $86.8 \pm 15.3^{*}$ & $84.9 \pm 10.5^{*}$ & $82.6 \pm 15.2^{* * *}$ & $83.5 \pm 12.5^{* *}$ & $77.6 \pm 12.9^{* *}$ & $79.6 \pm 12.6^{* * *}$ \\
\hline HR (beats/min) & $78.1 \pm 11.2$ & $78.4 \pm 9.9$ & $79.1 \pm 10.0$ & $75.9 \pm 9.6$ & $77.1 \pm 18.4$ & $78.2 \pm 12.0$ & $74.7 \pm 12.3$ & $77.0 \pm 14.8$ & $76.9 \pm 10.4$ \\
\hline
\end{tabular}

Data are given as mean \pm standard deviation $(\mathrm{n})$

$L C$ lanthanum carbonate
V.S. At the start, ${ }^{* *} P<0.001,{ }^{* *} P<0.01, * P<0.05$ 
every report indicated for lanthanum deposition in gastric mucosa, there is no relationship to gastrointestinal symptoms. In a nod to these reports, further long-term and large number observation should be needed.

Although several laboratory parameters showed statistically significant changes after 4 or 8 years, none of these parameters except for intact PTH and blood pressure were clinically significant when the mean changes from baseline and their confidence intervals are taken into account. At the start of the follow-up observational study (2009), a pronounced decrease of more than $100 \mathrm{pg} / \mathrm{mL}$ in intact PTH was observed. This decrease may be due to the introduction of cinacalcet in 2008 . Both systolic blood pressure (SBP) and diastolic blood pressure (DBP) also decreased significantly after 3 years. Although it is unknown why a clinically significant decrease in blood pressure was observed, the degree of decrease in SBP and DBP after 8 years (i.e. SBP $-18.83 \mathrm{mmHg}$, DBP $-13.39 \mathrm{mmHg}$ ) was a positive effect.

The serum $P$ concentrations were maintained within the management target range $(3.5-6.0 \mathrm{mg} / \mathrm{dL})$ recommended in the JSDT guidelines [6] for the entire 8 years. The longterm therapeutic effects of LC and other PBs on hyperphosphatemia were also confirmed in this study.

Hyperphosphatemia has been shown to increase mortality among patients with CKD [26]. Given this finding, management of serum $P$ in patients with CKD has been recognized as a treatment priority. Recent data suggest improved survival when $\mathrm{PB}$ is used in the dialysis of patients $[27,28]$. The results of other studies also suggest that there is a survival benefit associated with LC treatment $[29,30]$.

The present study has several limitations, the first of which is selection bias. We selected the patients who had completed the phase III study of LC, so we cannot exclude the possibility that only patients with no safety issues were enrolled in the study. Another potential limitation, as with any other long-term follow-up study, is the small number of enrolled patients. Regardless of these limitations, the results of the present study revealed no evidence of delayed adverse events or any increase in the incidence of LC-related adverse events with increasing LC exposure.

This study was might not able to put out the conclusion to safety about $\mathrm{LC}$, as there were a limited number of the cases available. However, these results are valuable to evaluate LC exposure for up to 8 years.

\section{Conclusions}

In patients who completed the 3-year phase III extension study of LC, no drug-related adverse events were reported during the follow-up observational study. Both patients who continued LC use and patients who switched to another $\mathrm{PB}$ experienced serious adverse events during the follow-up observational study; however, there was no difference in the frequency of these events in either group and no unexpected serious adverse events were observed. The observations reported so far are short-term, and none of them cover a period of more than 10 years. Thus, it appears that further detailed investigations are needed.

\section{Appendix}

Mihama Hospital, Chiba, Japan (PI: Takehiko Sakai); Mihama Narita Clinic, Narita, Japan (PI: Kouichi Murakami); Mihama Sakura Clinic, Sakura, Japan (PI: Osamu Nagakawa); Shin Kashiwa Clinic, Kashiwa, Japan (PI: Yasuo Kimura); Meiyo Clinic, Toyohashi, Japan (PI: Yoshinari Tsuruta); Shigei Medical Research Hospital, Okayama, Japan (PI: Masaki Fukushima); Nakajima Tsuchiya Clinic, Hiroshima, Japan (PI: Misaki Moriishi); Shimazu Hospital, Kochi, Japan (PI: Isao Takeda); Kochi Takasu Hospital, Kochi, Japan (PI: Kenji Yuasa); Kitasaito hospital, Asahikawa, Japan (PI: Atsushi Wada).

\section{Competing interests}

This study was funded by Bayer Yakuhin, Ltd. TS received honoraria from Bayer Yakuhin, Ltd. for delivering lectures. SN and MO have no conflicts to disclose. Editorial support, including writing assistance with draft development was provided by SunFlare Co., Ltd.

\section{Authors' contributions}

TS (corresponding author) has planned this study, has searched literatures, and has analysed and evaluated study data. And TS also wrote this manuscript. SN has applied to the Ethical Review Board and extracted data. MO took a statistical step and supported to evaluate study data. All authors read and approved the final manuscript.

\section{Acknowledgements}

For a list of institutions and principal investigators (PIs) see the appendix. The authors wish to thank the staff at all investigational sites.

Received: 3 September 2015 Accepted: 8 April 2016

Published online: 11 May 2016

\section{References}

1. Goodman WG, Goldin J, Kuizon BD, et al. Coronary-artery calcification in young adults with end-stage renal disease who are undergoing dialysis. N Engl J Med. 2000;342:1478-83.

2. Block GA, Klassen PS, Lazarus JM, Ofsthun N, Lowrie EG, Chertow GM. Mineral metabolism, mortality, and morbidity in maintenance hemodialysis. J Am Soc Nephrol. 2004;15:2208-18.

3. Kestenbaum B, Sampson JN, Rudser KD, et al. Serum phosphate levels and mortality risk among people with chronic kidney disease. J Am Soc Nephrol. 2005;16:520-8.

4. Melamed ML, Eustace JA, Plantinga $L$, et al. Changes in serum calcium, phosphate, and PTH and the risk of death in incident dialysis patients: a longitudinal study. Kidney Int. 2006;70:351-7.

5. Tentori F, Blayney MJ, Albert JM, et al. Mortality risk for dialysis patients with different levels of serum calcium, phosphorus, and PTH: the Dialysis Outcomes and Practice Patterns Study (DOPPS). Am J Kidney Dis. 2008:52:519-30.

6. Fukagawa M, Yokoyama K, Koiwa F, CKD-MBD Guideline Working Group; Japanese Society for Dialysis Therapy, et al. Clinical practice guideline for the management of chronic kidney disease-mineral and bone disorder. Ther Apher Dial. 2013;17:247-88.

7. Finn WF, SPD 405-307 Lanthanum Study Group. Lanthanum carbonate versus standard therapy for the treatment of hyperphosphatemia: safety and efficacy in chronic maintenance hemodialysis patients. Clin Nephrol. 2006;65:191-202. 
8. Hutchison AJ, Maes B, Vanwalleghem J, et al. Long-term efficacy and tolerability of lanthanum carbonate: results from a 3-year study. Nephron Clin Pract. 2006;102:c61-71.

9. Hutchison AJ, Barnett ME, Krause R, Kwan JT, Siami GA, SPD405-309 Lanthanum Study Group. Long-term efficacy and safety profile of lanthanum carbonate: results for up to 6 years of treatment. Nephron Clin Pract. 2008;110:c15-23.

10. Shigematsu T, Group LCR. Three-year extension study of lanthanum carbonate therapy in Japanese hemodialysis patients. Clin Exp Nephrol. 2010;14:589-97.

11. Canavese C, Mereu C, Nordio M, Sabbioni E, Aime S. Blast from the past: the aluminum's ghost on the lanthanum salts. Curr Med Chem. 2005;12:1631-6.

12. Molony DA, Murthy B. Accumulation of metals and minerals from phosphate binders. Blood Purif. 2005;23 Suppl 1:2-11.

13. Drüeke TB. Lanthanum carbonate as a first-line phosphate binder: the "cons". Semin Dial. 2007;20:329-32.

14. Aime S, Canavese C, Stratta P. Advisory about gadolinium calls for caution in the treatment of uremic patients with lanthanum carbonate. Kidney Int. 2007;72:1162-3.

15. Frazão JM, Adragão T. Non-calcium-containing phosphate binders: comparing efficacy, safety, and other clinical effects. Nephron Clin Pract. 2012:120:c108-19.

16. Parkinson IS, Ward MK, Kerr DN. Dialysis encephalopathy, bone disease and anaemia: the aluminum intoxication syndrome during regular haemodialysis. J Clin Pathol. 1981;34:1285-94.

17. Huang W, Liu J, Tang Y, Gao X, Di B, Zhang F. Efficacy and tolerability of lanthanum carbonate in treatment of hyperphosphatemia patients receiving dialysis-a systematic review and meta-analysis of randomized controlled trials. Curr Med Res Opin. 2014;30:99-108.

18. Shigematsu T, Lanthanum Carbonate Research Group. One year efficacy and safety of lanthanum carbonate for hyperphosphatemia in Japanese chronic kidney disease patients undergoing hemodialysis. Ther Apher Dial. 2010;14(1):12-9.

19. Zhai CJ, Yang XW, Sun J, Wang R. Efficacy and safety of lanthanum carbonate versus calcium-based phosphate binders in patients with chronic kidney disease: a systematic review and meta-analysis. Int Urol Nephrol. 2014:47(3):527-35.

20. Package insert of Fosrenol (Lanthanum Carbonate). Bayer Yakuhin, Ltd. 2013. version 8.

21. Davis RL, Abraham JL. Lanthanum deposition in a dialysis patient. Nephrol Dial Transplant. 2009;24(10):3247-50.

22. Makino M, Kawaguchi K, Shimojo H, Nakamura H, Nagasawa M, Kodama R. Extensive lanthanum deposition in the gastric mucosa: the first histopathological report. Pathol Int. 2015;65(1):33-7.

23. Namie S, Hamabe S, Kawatomi M, Oda H, Nakazawa M, Nishino T. Investigation of deposition of lanthanum on gastric mucosa in hemodialysis patients with lanthanum therapy. Nihon Toseki Igakkai Zasshi. 2015;48(3):169-77.

24. Haratake J, Yasunaga C, Ootani A, Shimajiri S, Matsuyama A, Hisaoka M. Peculiar histiocytic lesions with massive lanthanum deposition in dialysis patients treated with lanthanum carbonate. Am J Surg Pathol. 2015:39(6):767-71.

25. Rothenberg ME, Araya H, Longacre TA, Pasricha PJ. Lanthanum-induced gastrointestinal histiocytosis. ACG Case Rep J. 2015;2(3):187-9.

26. Block GA, Klassen PS, Lazarus JM, Ofsthun N, Lowrie EG, Chertow GM. Mineral metabolism, mortality, and morbidity in maintenance hemodialysis. J Am Soc Nephrol. 2004;15(8):2208-18.

27. Cannata-Andía JB, Fernandez-Martiwn JL, Locatelli F, et al. Use of phosphate-binding agents is associated with a lower risk of mortality. Kidney Int. 2013;84(5):998-1008

28. Isakova T, Gutierrez OM, Chang Y, Shah A, Tamez H, et al. Phosphorus binders and survival on hemodialysis. J Am Soc Nephrol. 2009;20(2):388-96.

29. Wilson R, Zhang P, Smyth M, Pratt R. Assessment of survival in a 2-year comparative study of lanthanum carbonate versus standard therapy. Curr Med Res Opin. 2009;25(12):3021-8.

30. Komaba H, Kakuta T, Suzuki H, Hida M, Suga T, Fukagawa M. Survival advantage of lanthanum carbonate for hemodialysis patients with uncontrolled hyperphosphatemia. Nephrol Dial Transplant. 2015;30(1):107-14.

\section{Submit your next manuscript to BioMed Central and we will help you at every step:}

- We accept pre-submission inquiries

- Our selector tool helps you to find the most relevant journal

- We provide round the clock customer support

- Convenient online submission

- Thorough peer review

- Inclusion in PubMed and all major indexing services

- Maximum visibility for your research

Submit your manuscript at www.biomedcentral.com/submit 